\title{
The Development of Peer Mediation Training for Senior High School Students
}

\author{
Budi Purwoko \\ Department of Guidance and Counseling \\ Universitas Negeri Surabaya \\ Surabaya, Indonesia \\ budipurwoko@unesa.ac.id
}

\begin{abstract}
This study aims to develop products and test the feasibility of products through expert validation and user validation. The tools of the mediation program that have been developed include (1) training guidebooks as mediators, (2) peer mediation model videos, (3) evaluation instruments resulting from the application of peer mediation. Product validators include 4 Guidance and Counseling experts and 5 school counselors. The feasibility test shows the product meets criteria of usability, feasibility, accuracy, propriety.
\end{abstract}

\section{Keywords—peer mediatio; senior high school students}

\section{INTRODUCTION}

In schools, conflict prevention and resolution approaches are security, punishment, and school-based programs. The security and punishment is a popular method, although it does not provide positive results for student's social skills. This method does not teach students to deal with conflict properly and correctly, does not give respect to individuals, weakens respect and empathy, injures mentallyphysically, and does not produce positive experiences in student's social interactions [1].

As school-based programs, peace education in schools is carried out in education activities for non-violence and conflict resolution [2]. This program is beneficial for increasing critical understanding of conflict and its solutions to develop harmony; the process of peacemaking and peacebuilding; win-win solution [3], provides positive results, especially knowledge, attitudes, and skills to resolve conflicts [4].

The problems faced in conflicts and violence were the conflict was left without any cultural, educative, and pedagogical prevention efforts. It is necessary to develop alleviate destructive conflict, such as peer mediation program in schools [5].

\section{METHOD}

The purpose of this development research is to produce a peer mediation program model that includes (1) peer mediation training manuals, (2) peer mediation video models, (3) evaluation instruments from peer mediation programs. It's developed based on references (a) Conflict Resolution: Strategies for Collaborative Problem Solving [5]; (b)
Mediation Model [6]; and (3) Problem Solving and Decision Making in Conflict Situations [7].

The design uses the Borg \& Gall (2003) model, with two main objectives, developing the product and testing the effectiveness of the product [8]. The adaptation of the development procedure is grouped into three main activities, (1) the pre-development stage, (2) the development stage, and (3) the post-development stage. This article describes the implementation of the pre-development and development stages [8].

In the pre-development stage applied needs assessment. This phase aims to produce data and descriptive knowledge of conflict in high school students which includes: patterns and ways to resolve conflicts, results and the consequences of the choice of how to manage conflicts, problems and obstacles faced in resolving conflicts that occur in schools, as well as hopes of resolution the right conflict. The results of the needs assessment are analyzed and reviewed based on the concepts and theories of conflict resolution. Furthermore, alternative patterns of conflict resolution are formulated. Needs assessment is done by distributing questionnaires to students and school counselors. The development phase is a step in preparing a prototype of a peer mediation program. Products developed include a set of peer mediation programs that include peer mediation training guides, mediation video models, and peer mediation outcome measurement instruments. This product tested for feasibility through expert testing and user testing. Data were analyzed with a content validity ratio (CVR) formulated by Lawshe [9]. The experts also write down product suggestions and criticisms.

\section{RESUlTS AND DISCUSSION}

There are three stages of product development to be discussed, including: (1) results of need assessment, (2) product development, (3) expert and user validations. The description of the three aspects is illustrated below.

\section{A. Need assessment}

Need assessment produces a set of knowledge about student's interpersonal conflict, the way to solve conflict, the results of conflict resolution, student involvement in handling conflicts in schools, problems and expectations to get conflict resolution assistance. Assessment carried out by distributing questionnaires to 550 students and 20 school counselor. Data 
show that $93 \%$ of students have experienced and are experiencing interpersonal conflict include disagreements, feuds, and physical fights. The pattern of conflict resolution were $67.3 \%$ of students allowing conflict as it is, and only $23.4 \%$ trying to resolve conflicts in various ways. Ways to deal with conflicts include: $39.2 \%$ avoidance, $28.4 \%$ leave, $18.7 \%$ fight, 13.7 dialogue. Based on this method, students use negative conflict resolution methods. Regarding the patterns and ways of resolving conflicts that have been carried out, $78.3 \%$ of students feel dissatisfied. Students' feelings when faced with conflicts are anger, fear, hatred, revenge, despair, anxiety. The ways of resolving conflicts applied by the school include: advising, punishment, and counseling assistance services. The obstacle to conflict resolution is that students are unable to resolve the conflict by themselves and students are reluctant to get help from the teacher. At school there is no peer mediation service. Teachers and students argue that there is a need for peer mediation services in schools.

The results of the literature study included topics of discussion about: (a) the concept of conflict and the characteristics of conflict, (b) conflict theories, (c) conflict resolution approaches, (d) individual psychological dynamics in interpersonal conflict, (e) constructive conflict resolution, (f) mediation procedures and decision making in conflict [10]. Overall the results of the literature study into conceptual material in the development of product research include: peer mediation training manuals, video mediation models, and evaluation instruments for conflict resolution results [11].

\section{B. Product: Peer Mediation Program}

The final product of this development is a set of peer mediation guidelines including: peer mediation training guides, mediation video models, instruments for evaluating peer mediation results including measuring perceptions, attitudes, ways of resolving, and the outcome of conflict resolution [3]. Product development is developed based on relevant literature (a) conflict resolution theory (b) "Conflict Resolution: Strategies for Collaborative Problem Solving" (c) "Mediation Model" and (d) "Problem Solving and conflict resolution [12].

The product of peer mediation training guides is a set of applicative instructions preparing students as a peer mediator. Students who receive peer mediation training are provided with knowledge of the basic concepts of conflict and skills in applying mediation as a way to resolve conflicts. The manual writing procedure refers to the pattern of experiential learning. Each chapter in the guide includes meeting preparation, introduction of concept material, group activities, and follow-up. The mediation training guide consists of three main materials: (1) basic concepts of conflict, (2) carrying out negotiations, and (3) mediation. In the first part of the material discussed the definition of conflict, causes of conflict, the process of conflict, methods of managing conflict, and strategies for resolving conflicts. In the second part of the material discussed the elements of negotiation, communication behavior in negotiations, procedures and negotiation stages. In the third part of the material discussed the elements of mediation, communication in mediation, and mediation procedures [13].

The mediation video model provides examples of how to behave, how to communicate, and how to practice each stage of mediation. This video plays the mediation of a mediator with two conflictors. The stages of mediation steps that are played include: preparing mediation, recognizing problems, facilitating problem solving, building agreements and terminations[3].

\section{Results of Expert and User Validation}

CVR scores on all items are positive so we can use product development. The expert CVI score of 0.896 and the user's CVI score of 0.967 are relatively high, so the categorized development products are appropriate to use. Experts consider the products developed to be very useful, very feasible, right, and very appropriate. Users consider that the products developed are very useful, feasible, appropriate and appropriate. Based on the results of expert and user validation, it is concluded that the product meets the eligibility criteria, so that it can be followed up in the effectiveness test

\section{CONCLUSION}

Based on the objectives and results of the research that has been carried out it can be concluded:

- This development research produces a set of peerprovided programs that include: (1) peer mediation training guidebooks; (2) peer mediation model videos; and (3) peer mediation outcome evaluation instruments.

- The results of the assessment of experts and product users state that in general the package products are eligibility criteria in four aspects,

a. Usability aspect, this development product is considered by experts and users to be very useful. This is based on the benefits provided in resolving students' interpersonal conflicts as well as providing experience to students in social roles, especially managing conflict positively.

b. The feasibility aspect, according to the assessment of experts and users of development products is included in the very feasible category because it is practical and effective.

c. Aspects of accuracy, according to experts and users of development products are considered appropriate. Peer mediation is right for high school. The mediation device has a density in terms of: (1) clarity of the formulation of general objectives and specific objectives, (2) conformity of material, (3) clarity of steps and accuracy.

d. The propriety aspect, according to the assessment of experts and users of development products, is considered appropriate because it is in accordance with values that apply to the community . 


\section{REFERENCES}

[1] R. Sathiparsad, "Addressing barriers to learning and participation: Violence prevention in schools," Perspectives in Education, vol. 21, pp. 99-111, 2003.

[2] S. Fountain, Peace education in UNICEF: Unicef, Programme Division, 1999.

[3] C. W. Moore, The mediation process: Practical strategies for resolving conflict: John Wiley \& Sons, 2014.

[4] S. W. Smith, A. P. Daunic, M. D. Miller, and T. R. Robinson, "Conflict resolution and peer mediation in middle schools: Extending the process and outcome knowledge base," The Journal of Social Psychology, vol. 142, pp. 567-586, 2002.

[5] H. B. Danesh, "Towards an integrative theory of peace education," Journal of peace education, vol. 3, pp. 55-78, 2006

[6] P. T. Coleman, M. Deutsch, and E. C. Marcus, The handbook of conflict resolution: Theory and practice: John Wiley \& Sons, 2014.

[7] E. Raider and S. Coleman, "Conflict Resolution: Strategies for collaborative problem solving," New York: Columbia University,
Teachers College. International Centre for Cooperation and Conflict Resolutio.

[8] G. Gall and J. P. Gall, "Borg.(2003)," Educational research: An introduction, vol. 7

[9] F. R. Wilson, W. Pan, and D. A. Schumsky, "Recalculation of the critical values for Lawshe's content validity ratio," Measurement and evaluation in counseling and development, vol. 45, pp. 197-210, 2012.

[10] J. A. Wall Jr and R. R. Callister, "Conflict and its management," Journal of management, vol. 21, pp. 515-558, 1995.

[11] O. Ramsbotham, H. Miall, and T. Woodhouse, Contemporary conflict resolution: Polity, 2011.

[12] M. A. Rahim, Managing conflict in organizations: Routledge, 2017.

[13] R. Silverstone, "The sociology of mediation and communication," The SAGE handbook of sociology, pp. 188-207, 2005. 